\title{
Preschool Asthma Symptoms in Children Born Preterm: The Relevance of Lung Function in Infancy
}

\author{
Manuel Sanchez-Solis 1,2,3,*®D, Maria Soledad Parra-Carrillo ${ }^{2}$, Pedro Mondejar-Lopez ${ }^{1,2}$, \\ Patricia W Garcia-Marcos ${ }^{1}$ and Luis Garcia-Marcos ${ }^{1,2,3}$ \\ 1 Pediatric Pulmonology Unit, Virgen de la Arrixaca University Hospital, Murcia University, \\ 30003 Murcia, Spain; mondejarp@gmail.com (P.M.-L.); part.garcia.marcos@gmail.com (P.W.G.-M.); \\ lgmarcos@um.es (L.G.-M.) \\ 2 Department of Surgery, Pediatrics, Obstetrics and Gynecology, University of Murcia, 30003 Murcia, Spain; \\ mariasoledadparrac@gmail.com \\ 3 Arrixaca Bioresearch Institute of Murcia, 30003 Murcia, Spain \\ * Correspondence: msolis@um.es; Tel.: +34-968-369-606
}

Received: 30 July 2020; Accepted: 7 October 2020; Published: 18 October 2020

check for updates

\begin{abstract}
Background: The aim of the study is to assess whether lung function of infants born preterm predicts wheezing in pre-school age. Methods: A survey of the core wheezing questionnaire of the International Study on Asthma and Allergy in Children was administered to parents of preterm newborns, to whom lung function tests were performed at a corrected age of six months, and who, at the time of the survey, were between three and nine years of age. Results: Low values of all lung function parameters measured, except FVC, were predictors of wheezing at some time in life, (FEV0.5 OR: 0.62 (95\%CI 0.39; 0.995); FEV0.5/FVC OR: 0.73 (0.54; 0.99)) FEF75 OR: 0.60 [0.37; 0.93]; FEF25-75 OR: $0.57(0.37 ; 0.89))$; and of wheezing in the past year (FEV0.5 OR: $0.36(0.17 ; 0.76)$; FEV0.5/FVC OR: 0.59 (0.38; 0.93); FEF75 OR: 0.38 [0.19; 0.76]; FEF25-75 OR: 0.35 (0.17; 0.70). In addition, FEV0.5/FVC values lower than the lowest limit of normality, were predictive of hospital admissions due to wheezing (OR: 3.07 ; $(1.02 ; 9.25)$ ). Conclusions: Limited lung function in infancy is predictive of both future wheezing and hospitalization for a wheezing episode.
\end{abstract}

Keywords: pre-school asthma; preterm newborn; infant lung function

\section{Introduction}

According to previous studies, children born preterm have an increased risk of wheeze and asthma as compared to children born at term. This risk is higher when gestational age is lower [1] and is independent of a family history of atopy [2]. Additionally, preterm children have lower lung function during their infancy than their counterparts born at term $[3,4]$ and this low lung function persists until school age $[5,6]$ and even into adulthood $[7,8]$.

Different perinatal factors have also been related with subsequent respiratory morbidity in children born preterm; including bronchopulmonary dysplasia (BPD) [5,6,8-10], intrauterine growth restriction [10,11], male sex [10] and Afro-American ethnicity [10], as well as non-perinatal factors: mainly, lower lung function, generally expressed in lower values of forced expiratory volume in the first second (FEV1), at the age when the study was performed [6].

One study [12] on the differences in lung function between infants with BPD and healthy ones, showed that the infants with BDP who presented recurrent wheeze had significant reductions in forced expiratory flow at $25 \%$ of the forced vital capacity (FEF25), and increased residual volume (RV), as compared to the normal infants. Furthermore, even when they were compared to their counterparts 
without wheeze, those infants who had suffered BPD and wheeze had both RV as well as the ratio between RV and the total lung capacity (TLC) significantly higher.

On the other hand, at least three cohorts that recruited healthy newborns to study risk factors for asthma inception have found that low lung function in infants is a risk factor for subsequent asthma [13-15], which suggests a very early origin of the condition; and that pre- and peri-natal factors must play an important role.

To the best of our knowledge, the relationship between lung function in preterm infants and respiratory morbidity at later ages has not been previously studied. Our objective is to study if, among children born prematurely, low values of different lung function parameters measured in infancy are risk factors for wheezing at pre-school age.

\section{Experimental Section}

\section{Methods}

Study population: This is a retrospective study, carried out on ex-preterm newborns, (gestational age under 32 weeks), to whom lung function tests were administered at a corrected age of six months and who, at the time of a telephone survey were between three and nine years of age. Children were born between 2010 and 2016. The initial sample included 167 patients, of whom a total of 142 accepted to participate. Patients who required oxygen beyond postmenstrual week 36 were diagnosed.

Telephone survey: Parents of the patients answered, over the telephone, the core wheezing questionnaire of the International Study on Asthma and Allergy in Children (ISAAC) http://isaac. auckland.ac.nz/resources/tools.php?menu=tools1), validated internationally.

Infant lung function: The forced vital capacity (FVC), the forced expiratory volume at $0.5 \mathrm{sec}$ $\left(\mathrm{FEV}_{0.5}\right)$, the forced expiratory flows at $75 \%$ and between $25 \%-75 \%$ of the $\mathrm{FVC}\left(\mathrm{FEF}_{75}\right.$ and $\mathrm{FEF}_{25-75}$, respectively) and the ratio of $\mathrm{FEV}_{0.5} / \mathrm{FVC}$ were measured at a corrected mean age of $27.7 \pm 1.94$ weeks, from the maximum expiratory curves obtained by means of the Rapid Chest Compression with Pre-insufflation technique in accordance with the American Thoracic Society and the European Respiratory Society (ATS-ERS) recommendations [16]. The tests were performed with Master-Screen Baby Body Plethysmograph equipment (Jaëger ${ }^{\circledR}$, Germany) and the pre-insufflation was by means of coupling the Neopuff neonatal resuscitator (Fisher \& Paykel Healthcare ${ }^{\circledR}$, New Zealand) with the face mask. All the infants were sedated with chloral hydrate at a dose of $80-100 \mathrm{mg} / \mathrm{Kg}$ and oxygen saturation was continually controlled using pulse oximetry.

Rehospitalizations due to respiratory causes: the number of admissions to hospital due to respiratory causes was obtained from review of the "Ágora" computer register of the Health Authority of Murcia, which records all admissions and their causes for all the population of the Region of Murcia, Spain. The policy regarding the use of Palivizumab, in our medium, is to administer it on the first day of life to all patients with BPD and to all the preterm newborns below 29 weeks of gestational age; thus, almost all the sample $(96 \%)$ was treated.

Statistical study: To calculate the power of the study, a variance in the z-score of $\mathrm{FEV}_{0.5}(0.76)$ found in this study has been considered. For a difference in the mean $\mathrm{FEV}_{0.5} \mathrm{z}$-score of 0.5 , a $95 \%$ confidence interval, and a power of $\geq 80 \%$, required a total of 48 patients per group.

The association between qualitative variables was tested by means of the analysis of the contingency tables using Pearson's Chi-squared statistic. Student's t-test was used to compare the means of the quantitative variables.

Additionally, multivariate regression logistic analyses were carried out, with the presence of wheezing in the past (yes/no) being the dependent variable and including the following independent variables: age at time of survey; sex; attending day-care/school (yes/no); presence of BPD; gestational age (weeks); birthweight z-score; allergic mother (yes/no); and z-score of each of the lung function parameters $\left(\mathrm{FVC}, \mathrm{FEV}_{0.5}, \mathrm{FEV}_{0.5} / \mathrm{FVC} \mathrm{FEF}_{75}\right.$ and $\mathrm{FEF}_{25-75}$ ) in different models: one model for each 
lung function parameter. The same analyses were performed considering exclusively wheeze in the past year (yes/no) as the dependent variable and with the same independent variables.

On the other hand, linear regression analyses were carried out, using the number of wheezing episodes as the dependent variable. The following were used as independent variables: age at time of survey; sex; attending day-care/school (yes/no); presence of BPD; gestational age (weeks); birthweight z-score; and allergic mother (yes/no). As in the previous case, the analyses were repeated including, as the independent variable, each of the results of the $\mathrm{z}$-score of the lung function parameters, with a different model for each one.

The study was approved by the Ethics Committee of the Virgen de la Arrixaca University Hospital from Murcia (ethical approval code: 2007-1-1-HCUVA).

\section{Results}

From the initial sample, which included 167 patients, a total of 142 (85.03\%) accepted to participate.

\subsection{Wheezing Ever}

Some $50 \%$ of the children studied presented wheeze at some point on their life (Table 1).

Table 1. Demographic characteristics, risk factors and lung function values and their differences between the children with or without ever wheezing.

\begin{tabular}{|c|c|c|c|c|}
\hline & $\begin{array}{l}\text { Total } \\
(142)\end{array}$ & $\begin{array}{l}\text { Wheezing: No } \\
\text { (72) }\end{array}$ & $\begin{array}{l}\text { Wheezing: Yes } \\
\text { (70) }\end{array}$ & $p^{*}$ \\
\hline Age (years) & $5.37(1.64)$ & $5.22(1.65)$ & $5.53(1.63)$ & 0.27 \\
\hline Number of episodes & - & - & $1.37(0.65)$ & - \\
\hline Gestational age (weeks) & $27.7(1.94)$ & $27.76(2.04)$ & $27.77(1.84)$ & 0.98 \\
\hline Birthweight (g) & $1034.3(309)$ & $1021.4(287.6)$ & $1047.6(331.1)$ & 0.62 \\
\hline Birthweight (z-score) & $-0.33(0.73)$ & $-0.37(0.79)$ & $-0.28(0.65)$ & 0.47 \\
\hline Corrected age at test (months) & $25.8(15.7)$ & $24.2(16.4)$ & $27.4(14.8)$ & 0.23 \\
\hline BPD & $88(62.0 \%)$ & $38(52.8 \%)$ & $50(71.4 \%)$ & 0.022 \\
\hline Invasive ventilation & $95(66.9 \%)$ & $48(66.7 \%)$ & $47(67.1)$ & 0.95 \\
\hline Day-care attendance in the first year & $97(68.3 \%)$ & $46(63.9 \%)$ & $51(72.9 \%)$ & 0.25 \\
\hline Male sex & $84(59.2 \%)$ & $44(61.1 \%)$ & $40(57.1 \%)$ & 0.63 \\
\hline Smoking during pregnancy & $27(19.3 \%)$ & $11(15.5 \%)$ & $16(23.2 \%)$ & 0.25 \\
\hline FVC (z-score) & $-1.12(0.57)$ & $-1.10(0.63)$ & $-1.14(0.51)$ & 0.72 \\
\hline $\mathrm{FEV}_{0.5}$ (z-score) & $-2.09(0.87)$ & $-1.94(0.93)$ & $-2.24(0.79)$ & 0.044 \\
\hline $\mathrm{FEV}_{0.5} / \mathrm{FVC}$ (z-score) & $-0.45(1.29)$ & $-0.27(1.36)$ & $-0.62(1.20)$ & 0.11 \\
\hline $\mathrm{FEF}_{75}$ (z-score) & $-1.47(0.91)$ & $-1.34(0.93)$ & $-1.61(0.87)$ & 0.07 \\
\hline $\mathrm{FEF}_{25-75}$ (z-score) & $-1.54(0.95)$ & $-1.35(0.97)$ & $-1.73(0.90)$ & 0.02 \\
\hline Allergic mother & $21(15.2 \%)$ & $5(7 \%)$ & $16(23.9 \%)$ & 0.008 \\
\hline $\begin{array}{l}\text { Rehospitalisation due to respiratory } \\
\text { causes }\end{array}$ & $37(18.4 \%)$ & $13(13.3 \%)$ & $24(23.3 \%)$ & 0.06 \\
\hline
\end{tabular}

Indicates number of cases (percentage) or mean (SD). * Difference between the proportion of children with wheezing according to each risk factor.

The univariate analysis showed that the presence of wheezing is associated with the z-score of different lung function measurements (FEV0.5, FEF75 and FEF25-75). The diagnosis of BPD constituted a consistent risk factor in all the multivariate analyses, independently of the lung function parameter included in it, with the OR value ranging from 2.45 (95\% CI 1.07-5.63), $p=0.03$ to 2.32 (95\% CI $1.01-5.35), p=0.047$. Likewise, the mother having allergy also constituted a consistent risk factor in all 
the multivariate analyses, independently of the lung function parameter included in it, with the OR value ranging from 5.51 (95\% CI 1.70-17.88), $p=0.005$ to 4.94 (1.53-15.96), $p=0.008$. The multivariate analysis showed that all the low lung function values analyzed, except FVC, were risk factors for wheezing at some time in their life (Figure 1).

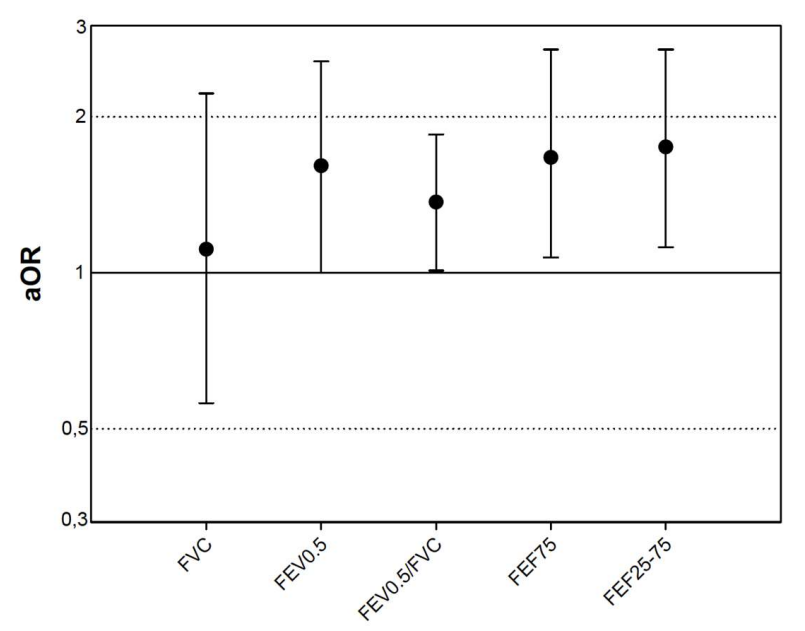

Figure 1. Risk of wheezing ever per z-score unit decrease of lung function. Adjusted odds ratios corrected for age, gender, daycare attendance, gestational age, birth weight (z-score), bronchopulmonary dysplasia, and allergic mother.

\subsection{Wheezing in the Past Year}

A total of $14.8 \%$ of the children studied presented wheezing in the past year (Table 2). There were statistically significant differences $(p=0.013)$ in the prevalence of wheezing between the patients with BPD $(24.6 \%)$ and no-BPD $(10.4 \%)$. The univariate analysis showed that the presence of wheezing in the past year was associated with the FEF25-75 z-score $(-1.47 \pm 0.95$ vs. $-1.93 \pm 0.91 ; p=0.04)$ (Table 2).

The multivariate analysis showed that all the lung function measurements analyzed, except FVC, were risk factors for wheezing in the past year (Figure 2), but suffering from BPD, although it showed a clear trend, was no longer a risk factor for wheezing in the past year (OR 2.46 (95\% CI 1.07-5.63), $p=0.03$ for the model that included FVC, but OR $3.16(95 \%$ CI $0.89 ; 11.18) p=0.074$ in the model that included FEV05/FVC). The mother having an allergy also constituted a consistent risk factor in all the multivariate analyses, independently of the lung function parameter included therein, with the OR ranging from 7.66 (95\% CI 1.67-35.04), $p=0.009$ to 5.61 (1.39-22.67), $p=0.015$.



Figure 2. Risk of wheezing during the last year per z-score unit decrease of lung function. Adjusted odds ratios corrected for age, gender, daycare attendance, gestational age, birth weight (z-score), bronchopulmonary dysplasia, and allergic mother. 
Table 2. Demographic characteristics, risk factors and lung function values and their differences between the children with or without wheezing in the last year.

\begin{tabular}{|c|c|c|c|c|}
\hline & $\begin{array}{l}\text { Total } \\
(\mathbf{1 4 2 )}\end{array}$ & $\begin{array}{c}\text { Wheezing in Last } \\
\text { Year: No } \\
\text { (121) }\end{array}$ & $\begin{array}{l}\text { Wheezing in Last } \\
\text { Year: Yes } \\
\text { (21) }\end{array}$ & $p^{*}$ \\
\hline Age (years) & $5.37(1.64)$ & $5.47(1.66)$ & $4.81(1.47)$ & 0.09 \\
\hline Number of episodes & $0.68(0.82)$ & $0.41(0.51)$ & $2.19(0.6)$ & $<0.001$ \\
\hline Gestational age & $27.77(1.94)$ & $27.75(1.94)$ & $27.86(1.98)$ & 0.82 \\
\hline Birthweight (g) & $1034.3(309)$ & $1014.3(295)$ & $1149.9(366)$ & 0.06 \\
\hline Birthweight (z-score) & $-0.33(0.73)$ & $-0.37(0.74)$ & $-0.07(0.62)$ & 0.07 \\
\hline Corrected age at test (sem.) & $25.8(15.7)$ & $25.6(16.4)$ & $26.7(11.1)$ & 0.77 \\
\hline BPD (yes) & $88(62 \%)$ & $72(59.5 \%)$ & $16(76.2 \%)$ & 0.15 \\
\hline Invasive ventilation (yes) & $95(66.9 \%)$ & $15(71.4 \%)$ & $80(66.1 \%)$ & 0.80 \\
\hline Day-care attendance in first year & $71(72.5 \%)$ & $54(68.9 \%)$ & $17(89.5 \%)$ & 0.06 \\
\hline Male sex & $62(63.3 \%)$ & $52(65.8 \%)$ & $10(52.6 \%)$ & 0.28 \\
\hline Smoking during pregnancy & $15(15.8 \%)$ & $11(14.5 \%)$ & $4(21.1 \%)$ & 0.49 \\
\hline FVC (z-score) & $-1.12(0.57)$ & $-1.11(0.60)$ & $-1.18(0.39)$ & 0.6 \\
\hline $\mathrm{FEV}_{0.5}$ (z-score) & $-2.09(0.87)$ & $-2.04(0.89)$ & $-2.36(0.72)$ & 0.12 \\
\hline $\mathrm{FEV}_{0.5} / \mathrm{FCV}$ (z-score) & $-0.45(1.29)$ & $-0.37(1.30)$ & $-0.89(1.15)$ & 0.09 \\
\hline $\mathrm{FEF}_{75}$ (z-score) & $-1.47(0.91)$ & $-1.42(0.90)$ & $-1.79(0.91)$ & 0.08 \\
\hline $\mathrm{FEF}_{25-75}$ (z-score) & $-1.54(0.95)$ & $-1.47(0.95)$ & $-1.93(0.91)$ & 0.04 \\
\hline Allergic mother (yes) & $15(16.3)$ & $11(14.9 \%)$ & $4(22.2 \%)$ & 0.48 \\
\hline $\begin{array}{l}\text { Rehospitalisation due to } \\
\text { respiratory causes }\end{array}$ & $36(18.4 \%)$ & $29(17.9 \%)$ & $8(20.5 \%)$ & 0.71 \\
\hline
\end{tabular}

Indicates number of cases (percentage) or mean media (SD). ${ }^{*}$ Difference between the proportion of children with wheezing according to each risk factor.

\subsection{Number of Wheezing Episodes}

On the other hand, the number of wheezing episodes referred by the parents was significantly greater in those children who still presented wheezing in the past year $(2.19 \pm 0.6$ vs. $0.41 \pm 0.51$; $p<0.001)$. However, the multivariate analysis showed that the number of exacerbations was related with all of the lung function parameters analyzed, except FVC, and having an allergic mother (Table 3), but attending day-care in the first year of life was not ( $\beta$ coef.: 0.18 ; $95 \%$ CI -0.11 to $0.47 ; p=0.227$ ).

Table 3. List of number of episodes, referred by the parents, with different independent variables.

\begin{tabular}{ccc}
\hline Variable & B Coef. $(\mathbf{9 5} \%$ CI) & $p$ \\
\hline FVC (z-score) & $-0.073(-0.33 ; 0.18)$ & 0.575 \\
\hline $\mathrm{FEV}_{0.5}$ (z-score) & $-0.20(-0.37 ;-0.04)$ & 0.015 \\
\hline $\mathrm{FEV}_{0.5} / \mathrm{FVC}$ (z-score) & $-0.13(-0.23 ;-0.03)$ & 0.015 \\
\hline $\mathrm{FEF}_{75}$ (z-score) & $-0.21(-0.36 ;-0.06)$ & 0.007 \\
\hline $\mathrm{FEF}_{25-75}$ (z-score) & $-0.22(-0.36 ;-0.07)$ & 0.003 \\
\hline
\end{tabular}

\subsection{Rehospitalisation Due to Respiratory Causes}

The number of patients admitted to hospital for respiratory reasons was 27/140, which amounted to $19.29 \%$ (in two cases we do not have the data as the patients left the Region of Murcia). Of the children diagnosed with BPD, 20.9\% were admitted to hospital on at least one occasion, compared to $16.7 \%$ of the preterm children without BPD $(p=0.534)$. No relationship was found between the variables studied and hospital admission or not due to respiratory causes. However, the multivariate 
analysis showed that a FEV0.5/FVC value lower than the lower limit of normality, was a risk factor for hospital admission (OR: $3.07 ; 95 \%$ CI 1.02 to $9.25 ; p=0.046$ )

\section{Discussion}

In this study on the prevalence of wheezing in pre-school age children who had been born preterm, with or without BPD, almost half of them presented wheeze ever; however, only 21 out of $142(14.8 \%)$ still presented wheeze in the past year, with the prevalence in children with BPD being slightly more than double as compared to those without BPD (18.2\% vs. $9.2 \%)$. This prevalence is somewhat lower than the data published from the EPICURE study [6] on wheezing at 11 years of age in former very preterm children who, in the past year, $21 \%$ still had wheeze; although an additional $25 \%$ were diagnosed with asthma or were under treatment with asthma medication for respiratory symptoms. The children in that study had a mean age of $10.9 \pm 0.38$ years, significantly older than those in our sample (5.37 \pm 1.64 years) and the percentage of patients with BPD was also higher in the EPICURE study $(71 \%$ vs. $62 \%)$. In children between three and five years of age, the prevalence of wheezing was reported as 32\% and 39\%, respectively, in BDP and non-BDP patients ( $p=0.51$ ) [17]; however, the children in that study were born between 1998 and 2001, and our cohort were born between 2010 and 2016, which may explain the difference in prevalence. One study carried out in Germany [18], in a group of nine-year-old children who had been born preterm with a very similar gestational age to that of the present study, found a prevalence of wheezing of $14 \%$ and $4 \%$ in BDP and non-BDP patients, respectively, albeit without statistical significance, although this was probably due to the reduced size of the sample, which included only 28 patients in each group. It also corresponded to children born between 1994 and 2002; much earlier than our sample.

The respiratory morbidity of these former preterm infants is not only frequent, but also shows a potential severity, since almost $20 \%$ have been admitted to hospital, at least once in their lives, due to respiratory causes. We have found no significant differences in hospital admissions among those children diagnosed with BPD $(20.9 \%)$ compared to those without $(16.7 \%)$. The survey carried out by Vrijlandt et al. [17] referred to hospital admissions only in the first three months of life and found differences between BPD and non-BPD patients $(54 \%$ vs. $14 \% ; p<0.001)$. The figures of rehospitalization in our study are, likewise, lower than those published by vom Hobe et al. [18] ( $36 \%$ and $21 \%$, respectively). It is possible that the birth year of the children in each of the studies (the present one is later), as well as the use of palivizumab, systematic in our case and which is not reported in these two studies, can explain the lower number of patients admitted to hospital in our sample. Independently of the presence of BPD, in the total group, we found no association between hospital admittance and wheezing in the past year (18.9\% vs. $21.6 \% ; p=0.706)$; although it almost reaches significance if we consider ever wheezing as opposed to never $(64.9 \%$ vs. $35.1 \%$; $p=0.06)$, probably as a consequence of those admitted due to bronchiolitis in the first year of life.

We have described for the first time, to the best of our knowledge, that infant lung function, essentially the obstructive pattern (FEV0.5/FVC) is a risk factor for respiratory morbidity: ever wheezing (Figure 1), wheezing in the past year (Figure 2) and also rehospitalization due to respiratory causes (FEV0.5/FVC < LLN: OR = 3.07; 95\% CI 1.02 to 9.25; $p=0.046$ ) in schoolchildren who were born preterm. It has been described that lung function in preterm children is lower with respect to their counterparts born at term, already in the infant stage [3] and that that alteration persists into school age [6] and even into adulthood [1]. Moreover, the preterm children who suffer BPD have a worse lung function than those born at term, during infancy [3,4], and even than the non-BPD preterm newborns [19], and this lost lung function, with regard to the healthy population, persists until school age $[5,6]$ and even into adulthood $[7,8]$. The association of respiratory morbidity and alterations in lung function present at the moment of the survey or evaluation [7] has likewise been described, although not in all studies $[2,6,18]$. This would suggest that it is not only a structural reason which explains the respiratory morbidity, and that there must be other yet to be identified factors. For instance, in our case having an allergic mother 
is an independent risk factor for wheezing, although not for rehospitalization, which contradicts other publications that showed that family atopy is not a risk factor for wheezing among preterm children [2].

This study presents several limitations: firstly, the assessment of wheezing was carried out by means of a questionnaire and, although widely used throughout the world, this technique is always more subject to bias than if the assessment had been prospective. However, we believe that this bias cannot occur in the case of rehospitalization, given that the method used is the regional registry in which the clinical records of each patients are kept. Another limitation of the study is that no study of atopy had been performed in the patients; even more so if we consider that a relationship has been observed between maternal atopy and risk of wheeze. We do not really know how this information may have affected the results modifying the relationship between early lung function and subsequent wheezing, but it is probable that - as occurs with maternal allergy - this factor could have been independent of the best or worst early lung function. It would probably have modified the relationship between allergy in the mother and the higher prevalence of wheezing.

\section{Conclusions}

In conclusion, and apart from corroborating prior studies regarding the high prevalence of respiratory morbidity among children who were preterm newborns, we have found that the limitation in lung function at an infant age is a predictive factor both for subsequent wheezing and also for rehospitalisation.

Author Contributions: Conceptualization, M.S.-S.; methodology, M.S.-S.; validation, M.S.-S., L.G.-M., P.M.-L., and P.W.G.-M.; phone surveys, M.S.P.-C.; writing — original draft preparation, P.W.G.-M.; writing-review and editing, M.S.-S., M.S.P.-C., P.M.-L., P.W.G.-M., L.G.-M. All authors have read and agreed to the published version of the manuscript.

Funding: This research received no external funding.

Acknowledgments: In this section you can acknowledge any support given which is not covered by the author contribution or funding sections. This may include administrative and technical support, or donations in kind (e.g., materials used for experiments).

Conflicts of Interest: The authors declare no conflict of interest.

\section{References}

1. Sonnenschein-van der Voort, A.M.; Arends, L.R.; de Jongste, J.C.; Annesi-Maesano, I.; Arshad, S.H.; Barros, H.; Basterrechea, M.; Bisgaard, H.; Chatzi, L.; Corpeleijn, E.; et al. Preterm birth, infant weight gain, and childhood asthma risk: A meta-analysis of 147,000 European children. J. Allergy Clin. Immunol. 2014, 133, 1317-1329. [CrossRef] [PubMed]

2. Edwards, M.O.; Kotecha, S.J.; Lowe, J.; Richards, L.; Watkins, W.J.; Kotecha, S. Management of Prematurity-Associated Wheeze and Its Association with Atopy. PLoS ONE 2016, 11, e0155695. [CrossRef] [PubMed]

3. Friedrich, L.; Stein, R.T.; Pitrez, P.M.; Corso, A.L.; Jones, M.H. Reduced lung function in healthy preterm infants in the first months of life. Am. J. Respir. Crit. Care Med. 2006, 173, 442-447. [CrossRef] [PubMed]

4. Friedrich, L.; Pitrez, P.M.; Stein, R.T.; Goldani, M.; Tepper, R.; Jones, M.H. Growth rate of lung function in healthy preterm infants. Am. J. Respir. Crit. Care Med. 2007, 176, 1269-1273. [CrossRef] [PubMed]

5. Doyle, L.W.; Cheung, M.M.; Ford, G.W.; Olinsky, A.; Davis, M.N.; Callanan, C. Birth Weight $<1501$ G and Respiratory Health at Age 14. Arch. Dis. Child. 2001, 84, 40-44. [CrossRef] [PubMed]

6. Fawke, J.; Lum, S.; Kirkby, J.; Hennessy, E.; Marlow, N.; Rowell, V.; Thomas, S.; Stocks, J. Lung function and respiratory symptoms at 11 years in children born extremely preterm: The EPICure study. Am. J. Respir. Crit. Care Med. 2010, 182, 237-245. [CrossRef] [PubMed]

7. Den Dekker, H.T.; Sonnenschein-van der Voort, A.M.M.; de Jongste, J.C.; Anessi-Maesano, I.; Arshad, S.H.; Barros, H.; Beardsmore, C.S.; Bisgaard, H.; Phar, S.C.; Craig, L.; et al. Early growth characteristics and the risk of reduced lung function and asthma: A meta-analysis of 25,000 children. J. Allergy Clin. Immunol. 2016, 137, 1026-1035. [CrossRef] [PubMed] 
8. Kotecha, S.J.; Edwards, M.O.; Watkins, W.J.; Henderson, A.J.; Paranjothy, S.; Dunstan, F.D.; Kotecha, S. Effect of preterm birth on later FEV1: A systematic review and meta-analysis. Thorax 2013, 68, 760-766. [CrossRef] [PubMed]

9. Evans, M.; Palta, M.; Sadek, M.; Weinstein, M.R.; Peters, M.E. Associations between Family History of Asthma, Bronchopulmonary Dysplasia, and Childhood Asthma in Very Low Birth Weight Children. Am. J. Epidemiol. 1998, 148, 460-466. [CrossRef] [PubMed]

10. Keller, R.L.; Feng, R.; DeMauro, S.B.; Ferkol, T.; Hardie, W.; Rogers, E.E.; Stevens, T.P.; Voynow, J.A.; Bellamy, S.L.; Shaw, P.A.; et al. Prematurity and Respiratory Outcomes Program. Bronchopulmonary Dysplasia and Perinatal Characteristics Predict 1-Year Respiratory Outcomes in Newborns Born at Extremely Low Gestational Age: A Prospective Cohort Study. J. Pediatr. 2017, 187, 89-97. [CrossRef] [PubMed]

11. Kindlund, K.; Thomsen, S.F.; Stensballe, L.G.; Skytthe, A.; Kyvik, O.; Backer, V.; Bisgaard, H. Birth Weight and Risk of Asthma in 3-9-year-old Twins: Exploring the Fetal Origins Hypothesis. Thorax 2010, 65, 146-149. [CrossRef] [PubMed]

12. Robin, B.; Kim, Y.J.; Huth, J.; Klocksieben, J.; Torres, M.; Tepper, R.S.; Castile, R.G.; Solway, J.; Hershenson, M.; Goldstein-Filbrun, A. Pulmonary Function in Bronchopulmonary Dysplasia. Pediatr. Pulmonol. 2004, 37, 236-242. [CrossRef] [PubMed]

13. Bisgaard, H.; Jensen, S.M.; Bønnelykke, K. Interaction between asthma and lung function growth in early life. Am. J. Respir. Crit. Care Med. 2012, 185, 1183-1189. [CrossRef] [PubMed]

14. Brooke, E.; Lucas, J.S.; Collins, S.A.; Holloway, J.W.; Roberts, G.; Inskip, H.; Godfrey, K.M.; Cooper, C.; Pike, K.C.; Southampton Women's Survey Study Group. Infant lung function and wheeze in later childhood in the Southampton Women's Survey. Eur. Respir. J. 2014, 43, 919-921. [CrossRef] [PubMed]

15. Pike, K.C.; Rose-Zerilli, M.J.; Osvald, E.C.; Inskip, H.M.; Godfrey, K.M.; Crozier, S.R.; Roberts, G.; Clough, J.B.; Holloway, J.W.; Lucas, J.S.; et al. The relationship between infant lung function and the risk of wheeze in the preschool years. Pediatr. Pulmonol. 2011, 46, 75-82. [CrossRef] [PubMed]

16. Lum, S.; Stocks, J.; Castile, R.; Davis, S. ATS/ERS Statement: Raised Volume Forced Expirations in Infants: Guidelines for Current Practice. Am. J. Respir. Crit. Care Med 2005, 172, 1463-1471.

17. Vrijlandt, E.J.; Boezen, H.M.; Gerritsen, J.; Stremmelaar, E.F.; Duiverman, E.J. Respiratory health in prematurely born preschool children with and without bronchopulmonary dysplasia. J. Pediatr. 2007, 150, $256-261$. [CrossRef] [PubMed]

18. Vom Hove, M.; Prenzel, F.; Uhlig, H.H.; Robel-Tillig, E.R. Pulmonary Outcome in Former Preterm, Very Low Birth Weight Children with Bronchopulmonary Dysplasia: A Case-Control Follow-Up at School Age. J. Pediatr. 2014, 164, 40-45. [CrossRef] [PubMed]

19. Sanchez-Solis, M.; Perez-Fernandez, V.; Bosch-Gimenez, V.; Quesada, J.J.; Garcia-Marcos, L. Lung function gain in preterm infants with and without bronchopulmonary dysplasia. Pediatr. Pulmonol. 2016, 51, 936-942. [CrossRef] [PubMed]

Publisher's Note: MDPI stays neutral with regard to jurisdictional claims in published maps and institutional affiliations.

(C) 2020 by the authors. Licensee MDPI, Basel, Switzerland. This article is an open access article distributed under the terms and conditions of the Creative Commons Attribution (CC BY) license (http://creativecommons.org/licenses/by/4.0/). 